\title{
$X$-ray crystal structures show DNA stacking advantage of terminal nitrile substitution in Ru-dppz complexes
}

Article

Accepted Version

McQuaid, K., Hall, J. P., Brazier, J. A., Cardin, D. J. and Cardin, C. J. (2018) X-ray crystal structures show DNA stacking advantage of terminal nitrile substitution in Ru-dppz complexes. Chemistry- A European Journal, 24 (59). pp. 15859-15867. ISSN 1521-3765 doi:

https://doi.org/10.1002/chem.201803021 Available at https://centaur.reading.ac.uk/78413/

It is advisable to refer to the publisher's version if you intend to cite from the work. See Guidance on citing.

To link to this article DOI: http://dx.doi.org/10.1002/chem.201803021

Publisher: Wiley

All outputs in CentAUR are protected by Intellectual Property Rights law, including copyright law. Copyright and IPR is retained by the creators or other copyright holders. Terms and conditions for use of this material are defined in the End User Agreement. 


\section{CentAUR}

Central Archive at the University of Reading

Reading's research outputs online 


\section{CHEMISTRY A European Journal}

\section{Accepted Article}

Title: X-ray crystal structures show DNA stacking advantage of terminal nitrile substitution in Ru-dppz complexes

Authors: Kane McQuaid, James Pearce Hall, John Alan Brazier, David John Cardin, and Christine Janet Cardin

This manuscript has been accepted after peer review and appears as an Accepted Article online prior to editing, proofing, and formal publication of the final Version of Record (VoR). This work is currently citable by using the Digital Object Identifier (DOI) given below. The VoR will be published online in Early View as soon as possible and may be different to this Accepted Article as a result of editing. Readers should obtain the VoR from the journal website shown below when it is published to ensure accuracy of information. The authors are responsible for the content of this Accepted Article.

To be cited as: Chem. Eur. J. 10.1002/chem.201803021

Link to VoR: http://dx.doi.org/10.1002/chem.201803021 


\title{
X-ray crystal structures show DNA stacking advantage of terminal nitrile substitution in Ru-dppz complexes
}

\author{
Kane McQuaid ${ }^{[a, c]}$, James P. Hall[ ${ }^{[a, b, c]}$, John A. Brazier ${ }^{[b]}$, David J. Cardin ${ }^{[a]}$ and Christine J. Cardin ${ }^{[a]^{*}}$
}

\begin{abstract}
The new complexes $\left[\mathrm{Ru}(\mathrm{TAP})_{2}(11-\mathrm{CN}-\mathrm{dppz})\right]^{2+}$, $\left[\mathrm{Ru}(\mathrm{TAP})_{2}(11-\mathrm{Br}-\mathrm{dpp} z]^{2+}\right.$ and $\left[\mathrm{Ru}(\mathrm{TAP})_{2}(11,12-\mathrm{diCN}-\mathrm{dpp})\right]^{2+}$ are reported. The addition of nitrile substituents to the dppz ligand of the DNA photooxidising complex $\left[\mathrm{Ru}(\mathrm{TAP})_{2}(\mathrm{dppz})\right]^{2+}$ promote $\pi-$ stacking interactions and ordered binding to DNA, as shown by X-ray crystallography.

The structure of $\Lambda$-[Ru(TAP $\left.)_{2}(11-C N-d p p z)\right]^{2+}$ with the DNA duplex d(TCGGCGCCGA) 2 shows, for the first time with this class of complex, a closed intercalation cavity with an AT base pair at the terminus. The structure obtained is compared to that formed with the 11- $\mathrm{Br}$ and 11,12-dinitrile derivatives, highlighting the stabilization of syn guanine by this enantiomer when the terminal basepair is GC. In contrast the AT basepair has the normal Watson-Crick orientation, highlighting the difference in charge distribution between the two purine bases and the complementarity of the dppz-purine interaction. The asymmetry of the cavity highlights the importance of the purine-dppz-purine stacking interaction.
\end{abstract}

\section{Introduction}

The complex $\left[\mathrm{Ru}(\mathrm{phen})_{2}(\mathrm{dppz})\right]^{2+}$ and its derivatives have been extensively studied since the original demonstration of the DNA 'light-switch' effect using $\left[\mathrm{Ru}(\mathrm{bpy})_{2}(\mathrm{dppz})\right]^{2+}$ (phen = phenanthroline, $\mathrm{dppz}=$ dipyridophenazine and bpy $=$ bipyridine). ${ }^{[1]}$ These complexes, and close derivatives, have been shown to be able to act as structure specific luminescent probes for mismatched DNA, ${ }^{[2,3]}$ and for G-quadruplexes..$^{[4,5]}$ Related complexes can oxidise guanine upon irradiation, ${ }^{[6-9]}$ explicitly directing DNA damage. ${ }^{[10]}$ Such damage pathways are utilized in the study of anti-cancer photodynamic therapies (PDT) ${ }^{[11-16]}$ for which ruthenium polypyridyl complexes are considered promising candidates for the next generation of photosensitizers. ${ }^{[13,16,17]}$ The extension of the dppz ligand with additional rings for example, leads to powerful anti-tumour properties. ${ }^{[18-20]}$ Gaining insight into the manner in which these

[a] K. McQuaid, Dr J. P. Hall, Prof D.J. Cardin, Prof C.J. Cardin Department of Chemistry, University of Reading, Whiteknights, Reading, RG6 6AD, UK.

E-mail: c.j.cardin@reading.ac.uk

[b] Dr J. P. Hall and Dr J. A. Brazier

Department of Pharmacy, University of Reading, Whiteknights, Reading, RG6 6AD, UK.

[c] K. McQuaid and Dr J. P. Hall

Diamond Light Source, Harwell Science and Innovation Campus, Didcot, Oxfordshire, OX11 ODE, UK

Supporting information for this article is given via a link at the end of the document. complexes bind to their target is therefore of importance, where a deeper structural knowledge allows for the superior design of more specific DNA binders. In one recent report, for example, a rapid screening approach was used to identify structural selectivity using racemic mixtures of a range of halide derivatives of $\left[\mathrm{Ru}(\mathrm{bpy})_{2} \mathrm{dppz}\right]^{2+}$, and including the $11-\mathrm{Br}$ analogue of the complex, studied in this work. ${ }^{[21]}$

$\left[\mathrm{Ru}(\mathrm{TAP})_{2}(\mathrm{bpy})\right]^{2+}(\mathrm{TAP}=1,4,5,8$-tetraazaphenanthrene $)$ has been shown to covalently link to guanine upon irradiation ${ }^{[6]}$ and the TAP ligand was subsequently used to form the photooxidising and DNA intercalating $\left[\mathrm{Ru}(\mathrm{TAP})_{2}(\mathrm{dppz})\right]^{2+}$ complex. ${ }^{[22]}$ That complex is the parent compound of the three derivatives reported here (Figure 1a). A detailed review of the photooxidation kinetics of $\left[\mathrm{Ru}(\mathrm{TAP})_{2}(\mathrm{dppz})\right]^{2+}$ with sequence specific guanine oligonucleotides has recently been published. ${ }^{[23]}$ The biophysical and solution behaviour of these complexes was intensively investigated in the absence of a structural model, until our publication in $2011^{[24]}$ highlighting the binding of $\Lambda-\left[\operatorname{Ru}(\mathrm{TAP})_{2}(\mathrm{dppz})\right]^{2+}$ to the DNA decamer sequence $\mathrm{d}(\mathrm{TCGGCGCCGA})_{2}$, and, the following year, the binding of $\Lambda^{-}$ $\left[\mathrm{Ru}(\text { phen })_{2}(\mathrm{dppz})\right]^{2+}$ to the sequence $\mathrm{d}(\mathrm{CCGGTACCGG})_{2 \cdot}{ }^{[25]}$ The

a
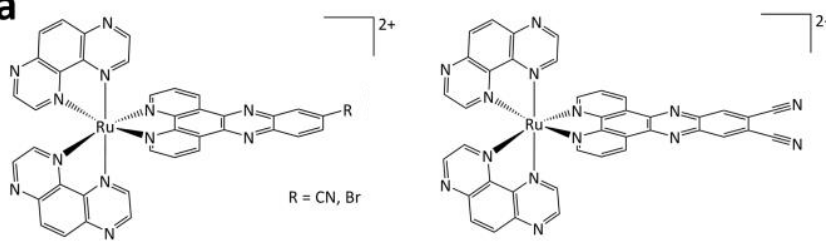

b

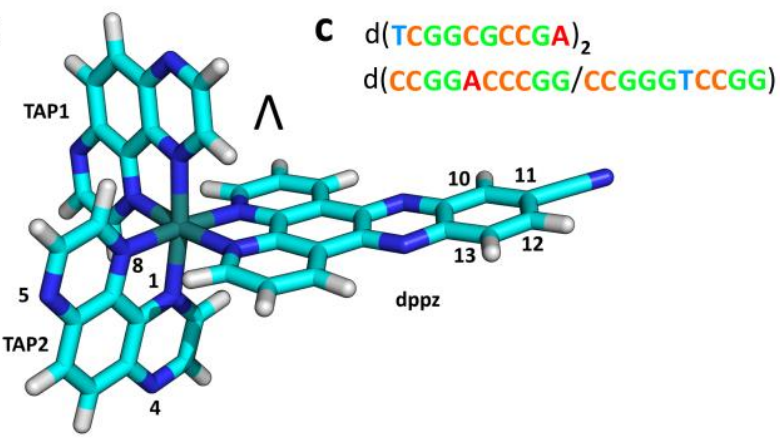

Figure 1 - Illustrations of (a) structures of the reported complexes $\Lambda$ $\left.\left[\mathrm{Ru}(\mathrm{TAP})_{2}(11-\mathrm{CN}-\mathrm{dpp} z]^{2+} \quad \text { (I), } \Lambda \text {-[Ru(TAP) }\right)_{2}(11-\mathrm{Br}-\mathrm{dppz})\right]^{2+}$ (II) and $\Lambda$ $\left[R u(T A P)_{2}(11,12-d i C N-d p p z)\right]^{2+}$ (III); (b) Stick plot of (I) showing the numbering scheme used throughout the text. Carbon atoms are coloured cyan, nitrogen - dark blue, ruthenium - teal and hydrogen - white; (c) oligonucleotides used in the study highlighting the standard nucleobase colouring used throughout.

complexes were shown to intercalate from the minor groove of the B-DNA, as confirmed by several further studies. ${ }^{[26]}$ The primary stabilising interaction was shown to be the stacking between the DNA bases and the dppz ligand. The angle of the (canted) intercalation was subsequently shown to be determined by a secondary stacking interaction between the phen or TAP ancillary ligand and the 2'-deoxyribose sugar of one of the four bases forming the intercalation cavity, thus altering the 
photophysical properties of the bound complexes. ${ }^{[27]}$ This binding mode is now seen to be the dominant binding mode for both enantiomers of $\left[R u(L)_{2}(d p p z)\right]^{2+}$ (where $L=$ bidentate $N$ heterocycle). The only exception recorded so far is the symmetrical binding of the lambda enantiomer to a central TA/TA step, which we now believe can only be seen at this site. ${ }^{[25]}$ In this binding mode there is a high twist angle of nearly $40^{\circ}$, with a secondary interaction with the two symmetrically equivalent phen ligands.

We were able to show that the angled intercalation mode is also seen for $\left[R u(b p y)_{2}(d p p z)\right]^{2+}$ and $\left[R u(p h e n)_{2}\left(11,12-M_{2}-d p p z\right)\right]^{2+}$ using a different DNA sequence, and also hypothesised that the angled (canted) intercalation mode seen at the symmetrical CG/CG step is a structural consequence of the projection of the $2-\mathrm{NH}_{2}$ group of guanine into the minor groove. ${ }^{[28]}$ More recently these structural observations have been used to interpret longstanding discussions in the literature about observations of multiple luminescence lifetimes even in apparently homogeneous Ru-DNA model systems. ${ }^{[29]}$ The realisation that the typical binding mode for these complexes is angled intercalation prompted the investigation of the effect of asymmetric substitution of the distal ring of the dppz ligand ${ }^{[30]}$ (positions 10-13 in Figure 1b).
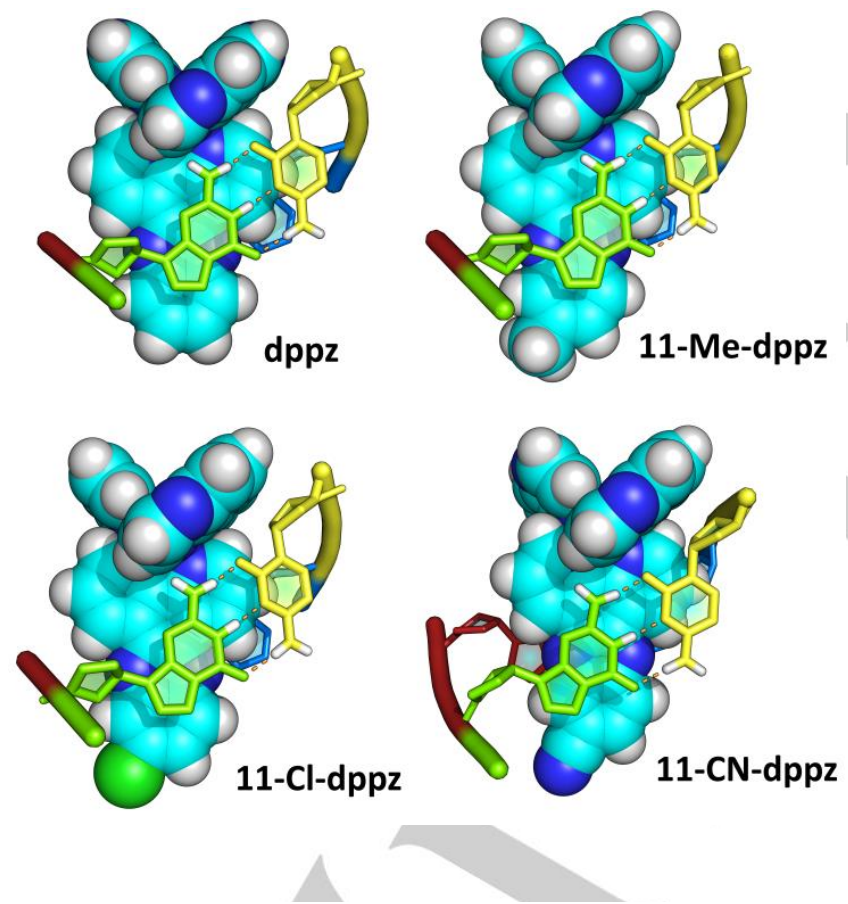

Figure 2 - Asymmetric angled binding by the lambda enantiomers of substituted $\left[\mathrm{Ru}(\mathrm{TAP})_{2}(\mathrm{dppz})\right]^{2+}$ complexes viewed from the C2-G9 base pair side. ${ }^{[17]}$ Of particular note is the similarity in binding between all complexes besides the 11-CN-dppz derivative.

Here we report the crystal structure of rac-[Ru(TAP) $)_{2}(11-\mathrm{CN}$ $\mathrm{dppz})]^{2+}(\mathbf{I})$, and the structural consequences of binding to the
DNA duplex d(TCGGCGCCGA) 2 , with a comparison to the CG/CG terminal step (Figure 1c). The phen analogue of this compound was recently described for potential photodynamic therapy applications..$^{[14]}$ The duplex is that used in our original publication from 2011, ${ }^{[24]}$ and our intention was to investigate the effect of electron withdrawing substituents with useful infrared reporting groups, ${ }^{[31]}$ and which could be accommodated in the solvent space of the well understood crystal packing. ${ }^{[32]}$ We make two comparisons, using two more new complexes - with the $\Lambda-11-\mathrm{Br}$ analogue (II) bound to the same sequence, and with the symmetric disubstituted $\Lambda$-[Ru(TAP $)_{2}(11,12-d i C N$ $\mathrm{dppz})]^{2+}(\mathrm{III})$ to an asymmetric decamer sequence.

We have previously observed with different derivatives of $\Lambda$ $\left[\mathrm{Ru}(\mathrm{TAP})_{2}(\mathrm{dppz})\right]^{2+}$ that intercalation into the terminal TC/GA base step can force the terminal adenine (A10) to flip out and form a reverse Watson-Crick base pair with a symmetry related strand. ${ }^{[27]}$ Therefore, as illustrated in Figure 2, the 'purine side' of the intercalation cavity was incomplete, even for an unsubstituted dppz. Perhaps most strikingly, we found that reversible dehydration of our original crystal exhibited a remarkable reversal, with the dehydrated form showing that the 'purine side' of the intercalation cavity was now intact, but the 'pyrimidine side' instead was the one which had flipped out. ${ }^{[33]}$ In this work we report that $\Lambda-11$-nitrile substitution gives us the first example of a complete TC/GA cavity at this terminal intercalation step, with the asymmetry of the cavity suggesting that the addition of a nitrile moiety can generate additional favourable $\pi$ orbital overlap, perhaps leading to enhanced specificity for DNA binding.|

\section{Results}

Synthesis and crystal structure of (I) with d(TCGGCGCCGA) 2. $\left[\mathrm{Ru}(\mathrm{TAP})_{2}(11-\mathrm{CN}-\mathrm{dppz})\right]^{2+}$ (I) was synthesized using a variation of a previously published method as both the $\mathrm{PF}_{6}^{-}$and $\mathrm{Cl}^{-}$salts. The racemic $\mathrm{PF}_{6}^{-}$salt was recrystallized from acetonitrile via the vapour diffusion of diethyl ether to give crystals suitable for X-ray diffraction. The $\mathrm{Cl}^{-}$salt was purified by chromatography and was then suitable for crystallization with the DNA sequence d(TCGGCGCCGA) 2 .

In some previous work we have found that well diffracting crystals could only be obtained with some DNA sequences by starting with the pure enantiomeric complex and the desired DNA oligonucleotide. In this case, the crystallisation was completely enantioselective and, on crystallization of the chloride salt of the racemic complex of the cation with the DNA decamer sequence d(TCGCCGCCGA $)_{2}$, red crystals were obtained. Diffraction data to $1.5 \AA$ resolution were collected on beamline 102 at Diamond Light Source Ltd. Data collection and refinement statistics are given in Table $\mathrm{S} 1$. 

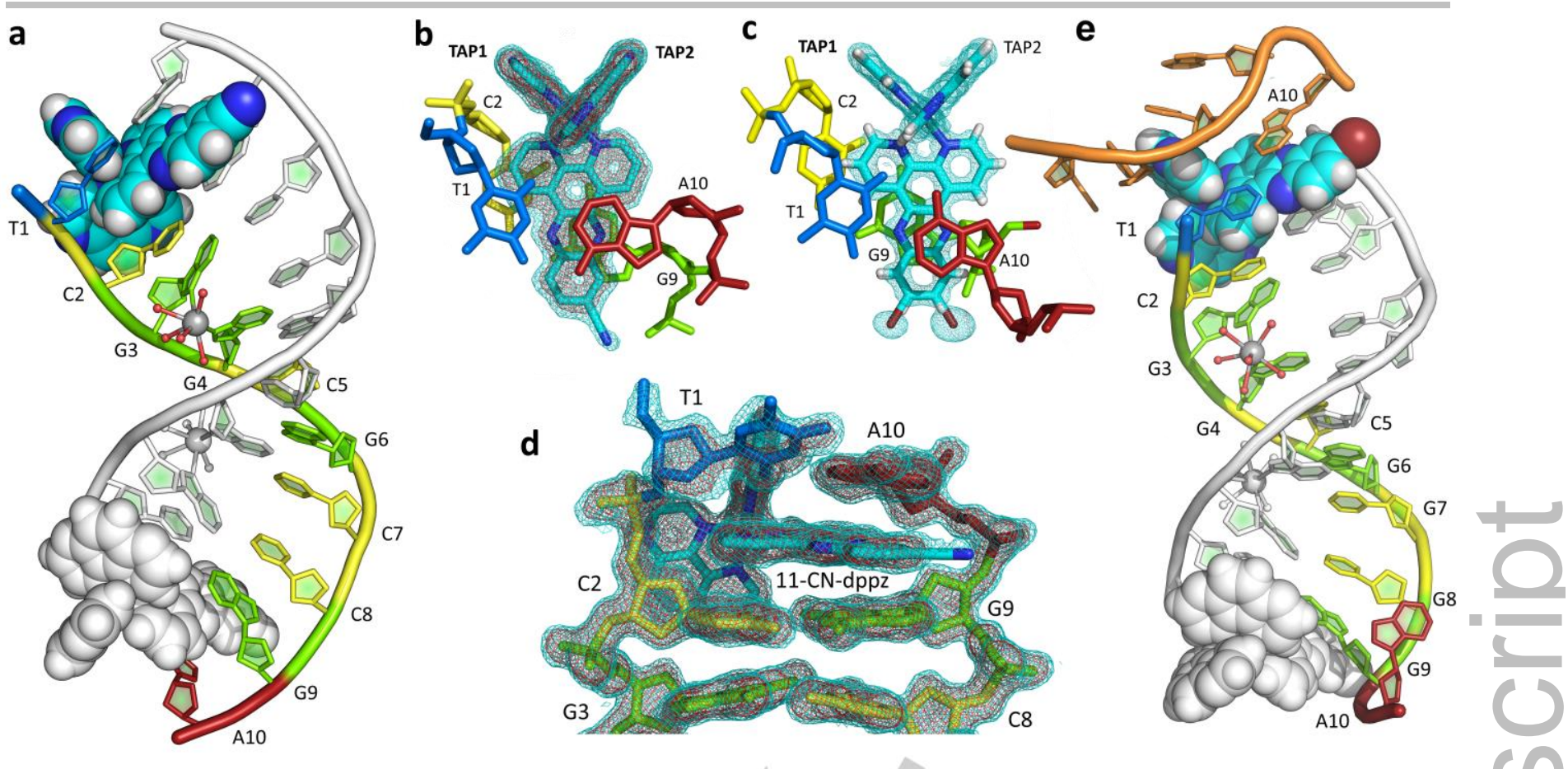

Figure 3 - The lambda enantiomers of (I) and (II) crystallised with the DNA sequence d(TCGGCGCCGA) 2. Any hydrogen atoms are shown in calculated positions. (a) The complete duplex assembly containing two asymmetric units (one coloured, one off white), omitting the symmetry generated complexes that interact at the G3G4/C7C8 step. The standard nucleic acid colour scheme of the Nucleic Acid Database is used for the bases, and $\mathrm{Ba}^{2+}$ ions have been coloured silver; (b) $2 \mathrm{~F}_{\mathrm{o}}-\mathrm{F}_{\mathrm{c}}$ electron density map for (I) showing the major orientation of the dppz ligand. The cyan map is countoured at $0.29 \mathrm{e} / \mathrm{A}^{3}$ and the red map at $0.44 \mathrm{e} / \AA^{3} ;$ ( (c) $2 \mathrm{~F}_{\mathrm{o}}-\mathrm{F}_{\mathrm{c}}$ electron density map for (II) showing the major and minor $\mathrm{Br}$
orientations, with map contoured at $0.29 \mathrm{e} / \AA^{3} ;$ (d) The ordered complete intercalation cavity with (I), contour levels as in (b); (e) The complete duplex assembly of (II) bound to orientations, with map contoured at $0.29 \mathrm{e} / \mathrm{A}^{3} ;(\mathrm{d})$ The ordered complete intercalation cavity with (I), contour levels as in (b); (e) The complete duplex assembly of (II) bound to
$\mathrm{d}$ (TCGGCGCCGA $)_{2}$ containing two asymmetric units and a symmetry related strand (shown in orange) that forms a reverese Hoogsteen base pair to complete the intercalation cavity.

What was quite unexpected, and previously unobserved, was the efficiency of the nitrile substituent in anchoring the terminal adenine base (A10), with the creation of a complete intercalation cavity at the terminal T1C2/G9A10 step of the duplex (Figure 3 $a, b, d)$. The complete assembly (Figure 3a) has twofold symmetry about the central steps. The orientation of the dppz ligand is determined by the contact between TAP1 and the 2'deoxyribose sugar of cytosine (Figure $3 \mathrm{~b}$ ). The bound dppz moiety is still not aligned with the Ru-N square plane (Figure $\mathrm{S} 3 \mathrm{~b}$ ). The level of detail visible at $1.5 \AA$ resolution (Figure S2) is sufficient to show partial disorder of the 11-CN substituent in the resulting structure. Electron density fitting revealed the presence of a minor component, giving the best fit at 0.33 occupancy. As with previously reported structures using this sequence, the crystals contained only the lambda enantiomer of the complex, at a binding stoichiometry of $1: 1$ complex to single DNA strand. Further details of backbone conformation and water structure are shown in Figures S3 and S4.

The structure shows a $\sim 50^{\circ}$ kink at the central G5C6/G5C6 step, previously seen in our reversible crystal dehydration study for the less hydrated form. ${ }^{[33]}$ In that work, the dehydration produced a remarkable switch from an open purine cavity, in the hydrated crystal, to an open pyrimidine cavity in the dehydrated crystal. In the present example, both sides of the cavity are complete, and the crystal form was obtained without the use of a humidity controlled environment. The asymmetry of the cavity is shown by the $\gamma$ backbone dihedral angles, which are $189^{\circ}$ on the 'pyrimidine side' and $63^{\circ}$ on the 'purine side' (see Discussion section and Table 1 for comparisons). Table S2 lists the derived parameters for all the structures discussed here, and Figures S5 and S6 show the extent of the stacking between the dppz ligand and the G9 base. The N7 of the guanine base is close to the 11-CN position. A barium cation originating from the crystallization solution is present in the major groove at the G3G4/C7C8 step, where TAP2 semi-intercalates, forming a 50 kink as we have previously observed, and which accounts for the complete enantioselectivity of the crystal packing. The $\mathrm{Ba}-\mathrm{Ba}$ distance is $8.0 \AA$, suggesting an intermediate degree of hydration, also supported by the short $c$ axial direction $(a=$ $47.88 \AA, c=29.14 \AA$ ) consistent with that previously reported. ${ }^{[33]}$ The orientation of the dppz chromophore is determined by the cytosine C2 sugar ring face contacts to the deoxyribose hydrogen atoms of $\mathrm{C}^{\prime}{ }^{\prime}, \mathrm{C}^{\prime}$ and $\mathrm{C}^{\prime}$ ' with the TAP2 ligand, as described in our previous paper concerning the effect of the orientation of inosine substitution at this position. ${ }^{[27]}$ The major orientation of the nitrile substituent is on the G9-A10 (the 'purine side') of the complete intercalation cavity. 

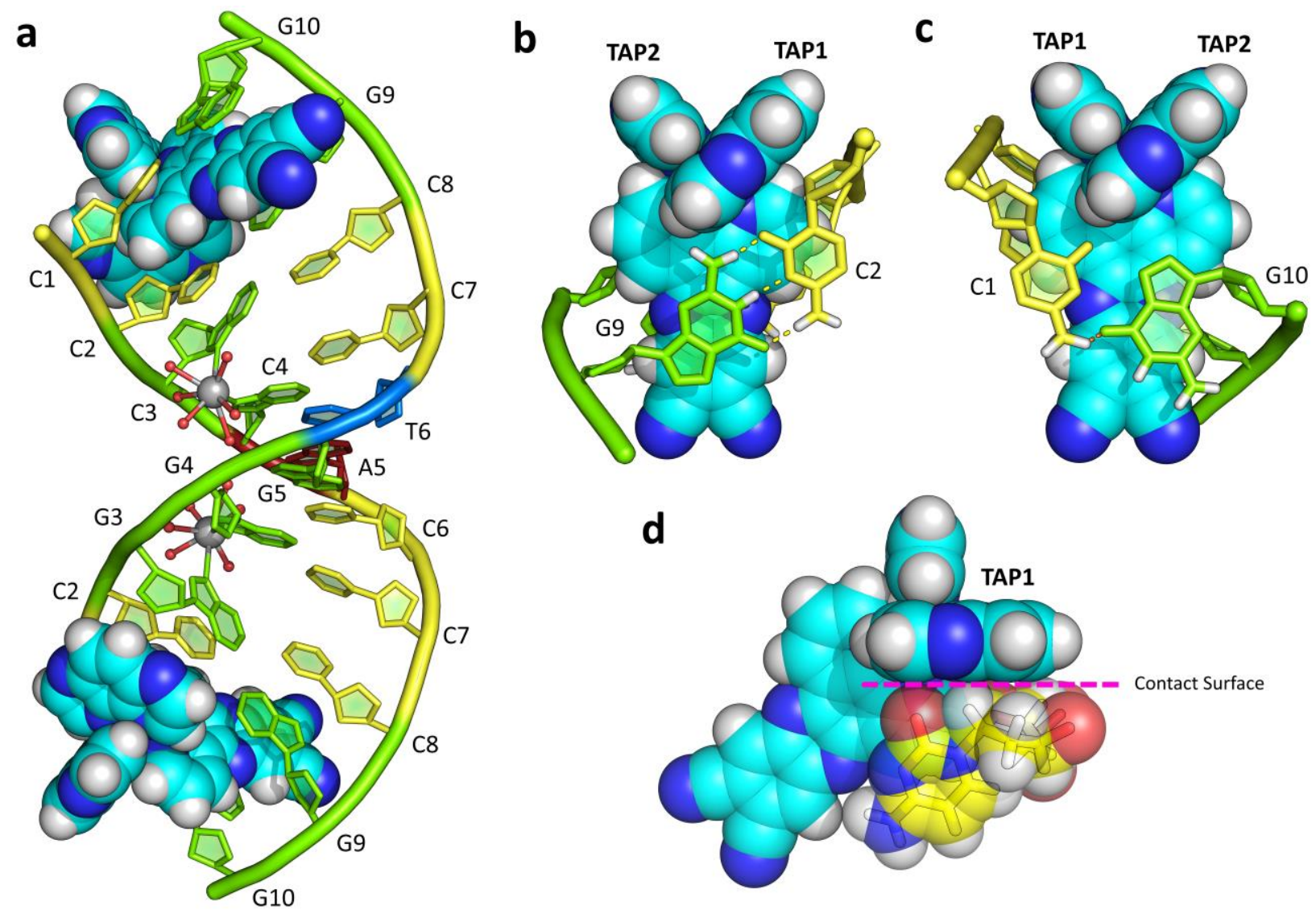

Figure 4 - The lambda enantiomer of (III) crystallised with the DNA sequences d(CCGGACCCGG) and d(CCGGGTCCGG), where both strands combine stoichiometrically. (a) shows the complete duplex assembly (one asymmetric unit) omitting the symmetry generated complexes that interact at the G3G4/C7C8 step. The structure was solved/refined in space group $\mathrm{P}_{3}$ where 50:50 disorder at the central step is observed (not shown). Standard nucleic acid colour scheme is used and $\mathrm{Ba}^{2+}$ ions have been coloured silver with red oxygen atoms (depicting water). Projections of the (b) C2-G9 and (c) C1-G10 base pair, onto the dppz ligand plane, omitting other residues. (d) Space filling representation of the

Crystal structure of (II) with d(TCGGCGCCGA) . [Ru(TAP) $)_{2}(11-$ $\mathrm{Br}-\mathrm{dppz})]^{2+}$ (II) was then synthesised using a variation of a previously published method as both the $\mathrm{PF}_{6}^{-}$and $\mathrm{Cl}^{-}$salts, with the latter used for crystallisation with DNA. The crystal structure of $\Lambda$-(II) with the sequence d(TCGGCGCCGA $)_{2}$ was determined to better than $1.1 \AA$ resolution (Table S1), giving an extremely clear map (Figure $3 c$ ). The structure obtained (Figure 3e) was isomorphous to that seen with the $\Lambda-11-\mathrm{Cl}$ analogue with a flipped-out $A 10$ stacked on a symmetry equivalent dppz ligand and 2:1 disorder of the 11-Br-dppz ligand. ${ }^{[30]}$ The major $\mathrm{Br}$ orientation is on the 'purine side' of the open intercalation cavity. Unlike the effect of $11-\mathrm{CN}$ substitution, there is no water network around the $\mathrm{Br}$ positions, despite the high data resolution and the location of 88 water molecules per DNA strand (Figures S7 and S8). The $\mathrm{Br}$ atom projects directly into the disordered part of the solvent space. The Ba-Ba distance in the major groove is $9.40 \AA$, as previously observed for the $\Lambda-11-\mathrm{Cl}$ analogue, and is associated with the fully hydrated form of this structure. A comparison of Figures $3 b$ and $3 c$ highlights the difference in adenine (A10) orientation resulting from the different intercalation cavities.

Crystal structure of (III) with d(CCGGACCCGG/CCGGGTCCGG). The symmetrical compound $\left[\operatorname{Ru}(T A P)_{2}(11,12-d i C N-d p p z)\right]^{2+}$ (III) was then synthesised for comparison. Attempted crystallisation of the racemic chloride salt with $d(\text { TCGGCGCCGA })_{2}$ was unsuccessful, but crystals were obtained with closely related decamer sequences. The best diffracting crystals, to $1.67 \AA$ resolution (Table $\mathrm{S} 1$ ), were obtained with the asymmetric central step A5C6/G5T6 generated by sequence combination d(CCGGACCCGG/CCGGGTCCGG) (Figure 1c and Figure 4). This crystal structure also showed complete cavity formation, and because of the central asymmetry, was solved and refined in the lower symmetry space group $\mathrm{P} 4_{3}$, in which the asymmetric unit is the full duplex, as shown in Figure 4a and Figures S9 and $\mathrm{S} 10$. The $\mathrm{CN}$ substituents protrude into the solvent cavity from the major groove of the DNA, as shown in Figures $4 b$ and $4 c$, and do not overlap directly with the DNA bases. Figure $4 d$ shows that the orientation of the dppz is determined by the TAP1-cytosine C2 contact, so that the nitrile groups are not contained within the DNA base stack. At the intercalation cavity there is evidence of backbone disorder, and the phosphate group of residue $\mathrm{G} 10$ was modelled as a mixture of $\mathrm{B}_{\mid}$and $\mathrm{B}_{\|}$ conformations. ${ }^{[34]}$ As we have previously seen with the unsubstituted dppz and this sequence, ${ }^{[25]}$ there is a reversal in the conformation of the terminal guanine base G10, so that it stacks in a syn conformation with the negative, and normally major groove face of the guanine stacked over the pyrazine ring, and aligning the $2-\mathrm{NH}_{2}$ vector direction of the guanine with one 
of the ligand - $\mathrm{CN}$ groups. Further details of map quality and water structure are shown in Figures S9 and S10.

\section{Discussion}

This first study of the comparative effect of nitrile and bromo substitution on dppz binding has highlighted both the effect of electron withdrawal and of an additional lone pair donor on the distal ring of the dppz. The structural evidence is that it affects both the base stacking and the solvent water interactions. a

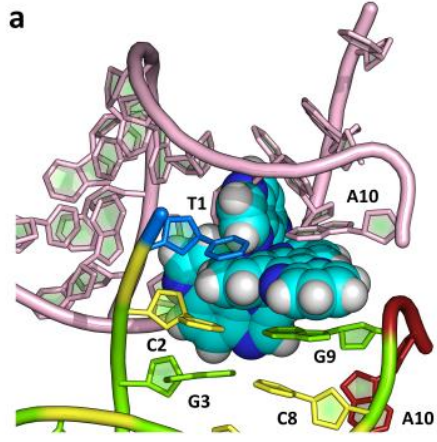

b

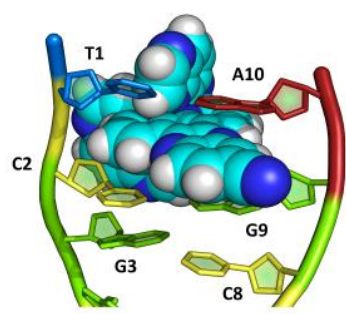

Figure 5 - Crystal structures of (a) $\Lambda-\left[\operatorname{Ru}(\mathrm{TAP})_{2}(\mathrm{dppz})\right]^{2+}$ and (b) $\Lambda-\left[\mathrm{Ru}(\mathrm{TAP})_{2}(11-\mathrm{CN}-\right.$ $\mathrm{dppz})]^{2+}$ bound to DNA sequence d(TCGGCGCCGA) 2 highlighting the differences in intercalation cavity. The symmetry related strand is shown as light pink showing how the cavity and gauche $\gamma$ torsion angle.

Cavity stabilisation/base stacking. The structural work reported here shows the unexpected effect of a substituent nitrile on the dppz ligand in stabilising the intercalation cavity formed by a TA basepair (Figure 5). It causes the T1-C2 side of the intercalation cavity to adopt the expanded backbone conformation with $\gamma$ dihedral angle of $189^{\circ}$ (Table 1 and Figure S3). Our previous work on the structure of $r a c-\left[R u(p h e n)_{2} d p p z\right]^{2+}$ with the hexamer duplex d(ATGCAT $)_{2}$ also showed asymmetric complete cavities, for both enantiomers of the complex, and in that work could be directly related back to the luminescence behaviour of the enantiomers. ${ }^{[26]}$ The crucial effect of backbone expansion on luminescence behaviour is the increased exposure of the dppz ligand to luminescence quenching, due to the additional hydrogen bonding by solvent water. X-ray crystallography has been uniquely useful in interpretation of such differences.

Table 1 - Selected y dihedral angles $\left(^{\circ}\right)$ for crystal structures of $\mathrm{d}(\text { TCGGCGCCGA })_{2}$ with a range of derivatised dppz complexes.

\begin{tabular}{cccc} 
Complex & PDB Accession № & $\gamma(\mathrm{T} 1 / \mathrm{C} 2)$ & $\gamma(\mathrm{G} 9 / \mathrm{A} 10)$ \\
\hline$\Lambda-\left[\mathrm{Ru}(\mathrm{TAP})_{2}(10-\mathrm{Me}-\mathrm{dppz})\right]^{2+}$ & $4 \mathrm{MJ9}$ & 58.4 & 187.2 \\
$\Lambda-\left[\mathrm{Ru}(\mathrm{TAP})_{2}(11-\mathrm{Me}-\mathrm{dppz})\right]^{2+}$ & $4 \mathrm{X} 18$ & 59.7 & 189.5 \\
$\Lambda-\left[\mathrm{Ru}(\mathrm{TAP})_{2}\left(10,12-\mathrm{Me} \mathrm{e}_{2}-\mathrm{dppz}\right)\right]^{2+}$ & $4 \mathrm{X} 1 \mathrm{~A}$ & 59.9 & 190.7 \\
$\Lambda-\left[\mathrm{Ru}(\mathrm{TAP})_{2}\left(11,12-\mathrm{Me}_{2}-\mathrm{dppz}\right)\right]^{2+}$ & $4 \mathrm{E} 8 \mathrm{~S}$ & 59 & 186.5 \\
$\Lambda-\left[\mathrm{Ru}(\mathrm{TAP})_{2}(11-\mathrm{Cl}-\mathrm{dppz})\right]^{2+}$ & $4 \mathrm{III}$ & 57.7 & 194 \\
$\Lambda-\left[\mathrm{Ru}(\mathrm{TAP})_{2}(11-\mathrm{Br}-\mathrm{dppz})\right]^{2+}$ & $6 \mathrm{GLD}$ & 55.6 & 61.2 \\
$\Lambda-\left[\mathrm{Ru}(\mathrm{TAP})_{2}(11-\mathrm{CN}-\mathrm{dppz})\right]^{2+}$ & $5 \mathrm{NBE}$ & 188.9 & 63.2
\end{tabular}

Table 1 compares the dihedral angles derived in the present work for the T1C2/G9A10 step with those from our previous work on $-\mathrm{Cl}$ and $-\mathrm{Me}$ substitution, which in every case gave $\gamma$ dihedral angles in the gauche range of $57-60^{\circ}$ on the pyrimidine side. ${ }^{[30,35]}$ In all these cases the cavity was incomplete. Interestingly, for the first time with the $11-\mathrm{Br}$ substitution we see a gauche dihedral angle at the purine G9-A10 as well, which on closer inspection reveals that, what in the other structures is an unfavourable interaction, may instead be an attractive interaction between the $\mathrm{C}^{\prime}-\mathrm{OH}$ and the bromine atom, with an $\mathrm{O}^{\prime}-\mathrm{Br}$ separation of $4.2 \AA$.

The closure of the intercalation cavity with the $11-\mathrm{CN}$ substituent suggest both strong electron withdrawal and a favourable stacking interaction. Since intercalation is favoured by the $\pi-\pi$ stacking interactions of the intercalating moiety with the surrounding base pairs, altering the $\pi$ quadrupole of the interacting complex should modify the binding affinity. Nucleobases, especially guanine, are electron rich, and due to the electrostatic repulsions caused by direct overlap of $\pi$ orbitals, sandwich and parallel-displaced stacking formations favour less negative $\pi$ density. Therefore the electron withdrawing nitrile group on the ligand presumably polarises the dppz, relocating $\pi$ electron density away from the interacting $\pi$ orbitals, rationalising the favourable $\pi-\pi$ stacking interactions seen here. This observation suggests a design lead for more specific binding agents, by the direct modification of the $\pi$ framework. Perhaps in this manner much weaker bound base steps or base mismatch/mutations could be targeted by such fine tuning of electronic properties. The targeting of mismatches probably requires enantiomer separation, since that is (structurally) a property of the delta enantiomer. [36,37] Such distal ring derivatisation has been shown to increase cellular uptake and heighten the potency of the proposed PDT photosensitizers. ${ }^{[13]}$

Nitrile group orientation and water structure. The major orientation of the 11-CN substituent, shown in both Figures 3 and 5 , and for the 11- $\mathrm{Br}$ substituent in Figure 3, corresponds to that previously seen for $11-\mathrm{Me}$ and $11-\mathrm{Cl}$ substitution. ${ }^{[30,35]}$ The effect on the water structure is different, however. Here we observe direct hydrogen bonding to the nitrile $\mathrm{N}$ atom when bound to DNA (Figure S4), also present with the 11,12-diCN ligand (Figure S10), creating additional water ordering. Strikingly, the methyl group substitution seen with the asymmetric 10-Me-, $11-\mathrm{Me}$ - and $10,12-\mathrm{Me}_{2}-\mathrm{dppz}^{[35]}$ are the most strongly directional (where total ordering was seen with X-ray data to $0.9 \AA$ resolution in each of these cases), and here the ordered water creates a cage around the ligand, but there is no ordered water structure around the methyl groups in the major groove (Figure S11). The 11- $\mathrm{Br}$ structure studied in this work is a substituent with a steric effect very similar to that of methyl group, and also does not generate any water ordering (Figure S8b). The methyl 
group is also the most hydrophobic and electron donating of those studied, but nevertheless did not stabilise the intercalation cavity. This difference suggests that we can distinguish hydrophobic, steric, and electronic effects on orientation, and propose that the alternative orientation for methyl substituents is strongly disfavoured by the preference of the more hydrophobic substituent to remain within the intercalation cavity rather than project into the major groove. Intercalatory interactions are energetically favourable, especially so when intercalation disturbs the hydration sphere of the binding site such as with the methylated complexes. Such logic has been used to explain why the binding constant for analogous methylated complexes is larger than that of the unsubstituted parent. [38] Therefore we hypothesise that the effects on orientation of asymmetrically substituted moeties are not only a consequence of a balance between the attractive polar contacts/Van der Waals forces and the increased entropy of hydration on binding, but additionally the hydrophobicity of the dppz substituent. Further systematic studies will be needed to confirm this proposal.

Stabilisation of syn guanine. A final point of note is the role of purines in the stabilising of stacking interactions, particularly the different adenine and guanine orientations consistent with their differing polarities, and previously seen with the unsubstituted dppz ligand. ${ }^{[25]}$ Figure 6 summarises this difference, comparing both the two purine bases as well as the introduction of the electron withdrawing substituent. The adenine base stacks on the 11-CN dppz ring to give a normal AT basepair, with the 6amino substituent pointing towards the major groove and the depth of intercalation determined by the hydrogen atom at the 2position. In contrast, the guanine base stacks directly over the 11,12-diCNdppz ligand, with the 6-carbonyl group directed away from the nitrile substituents and over one pyrazine $\mathrm{N}$ atom. The amino substituent, in the 2-position, is again directed toward the major groove and the nitrile substituents. The guanine is thus stabilised in a syn conformation, even though there is no stabilisation due to additional hydrogen bond formation.

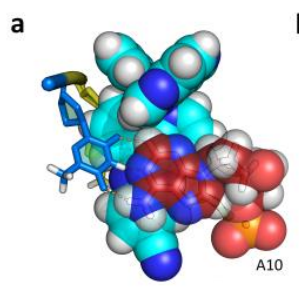

d

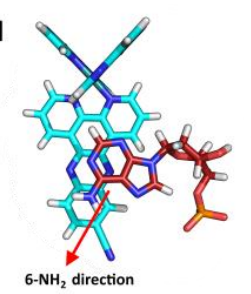

b c
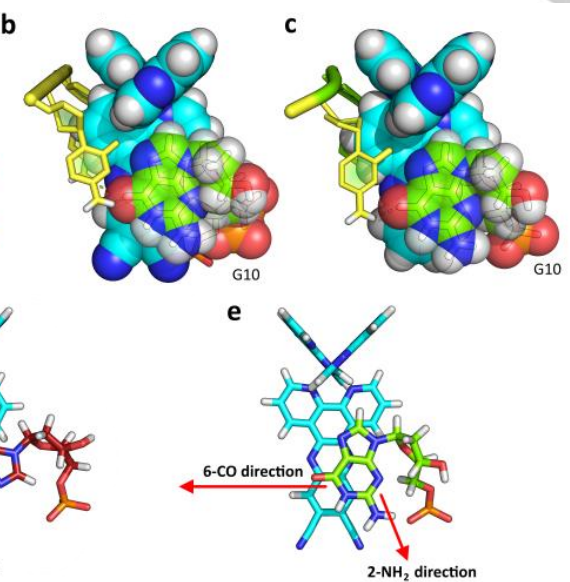

Figure 6 - Adenine and guanine stacking with the dppz ligand, showing the connection to base polarity. Adenine adopts the anti (Watson-Crick) conformation, wheras guanine adopts the syn (Hoogsteen) conformation. The difference can be related to the polarity of the bases. (a) The stacking of A10 on the 11-CN substituted dppz, seen for the first time in this work; (b) the stacking of G10 on the 11,12-diCN-dppz time in this work; (b) the stacking of G10 on the 11,12-diCN-dppz chromophore, reported here. (c) Comparison with the corresponding dppz-G10 stacking seen directionality of the polarity of the bases.
A new conclusion which can be drawn is that the guanine alignment is unaffected by the introduction of the electron withdrawing substituent. Comparing Figures $6 \mathrm{~b}$ and $6 \mathrm{c}$, the guanine orientation is almost identical, with no contact to the ancillary TAP or phen ligand, but a precise alignment of the carbonyl group over one pyrazine $\mathrm{N}$. The adenine comparison is now possible because of the effect of the 11-CN substitution in figure $6 \mathrm{a}$. Here the adenine $\mathrm{H} 2$ is in contact with the TAP2 ligand and may therefore influence the depth of intercalation. Figures $6 \mathrm{~d}$ and $6 \mathrm{e}$ show the greater stacking of the guanine compared to adenine, and the differing amino and carbonyl orientations.

Substituted dppz ligands bound to platinum have shown interesting G-quadruplex binding properties, [39] and this area merits further study, as syn-guanine stabilisation could be key to the conformation adopted. [5]

\section{Conclusions}

In our crystallographic studies of ruthenium polypyridyl complex/oligonucleotide interactions, we have sought to provide a rationale for the design of new, more structurally specific compounds, and a means of interpreting biophysical data. The present work evolved from this approach, where the new compounds were chosen for their probable crystallisability and desirable TRIR reporting abilities. They have shown the orienting effect of asymmetric dppz substitution but also the unexpected additional stability conferred on the intercalation cavity by a single nitrile group, a property not shared by halogen or methyl substitution. We propose that by altering the electronic quadrupole moment of the dppz by substituent effects we create a preferable $\pi$-stacking arrangement for intercalation, and can infer that by controlling the electronic properties further we may see a higher specificity for electron rich or deficient base steps. Further, based on previous structures we suggest that the orientation of asymmetrically derivatised intercalators will depend on the hydrophobicity of the substituents, an observation which will aid the design of better targeted intercalators. A systematic understanding of such interactions is indispensable in improving our comprehension of the excited state photophysics of these systems, where structural knowledge helps to elucidate observations in solution phase.

Further studies with other substituents will allow us to further understand the balance between electronic, hydrophobic and steric effects. Further comparative studies are also required to establish whether the syn guanine stabilisation is enantiospecific. To date it has not been observed for the delta enantiomer.

\section{Experimental Section}

\section{Synthetic Reagents and Materials}


Unless otherwise stated, all materials and chemicals were sourced from Sigma Aldrich (Merck) or Honeywell research chemicals. Sephadex C-25 stationary phase anion exchange resin was purchased from GE Healthcare. All solvents, unless otherwise stated, were obtained at HPLC grade and used without further purification. Where further purification was needed, protocol from "Purification of Laboratory Chemicals, $4^{\text {th }}$ edition, Armarego et. al." was followed. Deuterated solvents for NMR analysis were purchased either through Sigma-Aldrich or Cambridge Isotope Laboratories.

\section{Synthesis of Ruthenium Complexes (I) - (III).}

Syntheses of the novel nitrile derivatives of $\left[R u(T A P)_{2}(d p p z)\right]^{2+}$ were carried out by modifying existing literature methods. ${ }^{[22]}$ Both were prepared via the condensation of the relevant aromatic diamine with $\mathrm{Ru}(\mathrm{TAP})_{2} \mathrm{Cl}_{2}$, all of which were also synthesised by modifying our previously published literature methods. ${ }^{[30,35]} \mathrm{Ru}(\mathrm{TAP})_{2} \mathrm{Cl}_{2}$ (81 mg, $0.15 \mathrm{mmol}$ ) and 11-CN-dppz (49 $\mathrm{mg}, 0.16 \mathrm{mmol}$ ) (or 11,12-diCN-dppz (53 mg, 0.16 mmol)/11-Br-dppz (58 mg, $0.16 \mathrm{mmol})$ ) were suspended together in an aqueous ethanol solution $(7 \mathrm{~mL}, 1: 1)$ within a CEM microwave tube $(10 \mathrm{~mL})$. The violet coloured solution was degassed/evacuated with $\mathrm{Ar}$ for 15 minutes before being fully sealed and installed into a microwave synthesiser. The sample was irradiated at $140 \mathrm{~W}$ at $60^{\circ} \mathrm{C}$ for 40 minutes, yielding a deep $\mathrm{red} / \mathrm{brown}$ solution which was allowed to cool and then filtered in vacuo. Subsequent precipitation of the target compound from the filtrate was achieved by metathesis via dropwise addition of a saturated solution of aqueous potassium hexafluorophosphate $\left(\mathrm{KPF}_{6}\right)$. Isolation of the $\mathrm{PF}_{6}$ salt by suction filtration yielded a dark orange/brown solid, which, after washing with cold water (2 $x 2 \mathrm{~mL}$ ) was allowed to dry in air. Conversion to the chloride form was achieved by the dissolution of the crude material in a minimal amount of acetonitrile $(\sim 5 \mathrm{~mL})$, addition of HPLC grade water $(10 \mathrm{~mL})$, followed by dry, washed, Amberlite ion exchange resin (IRA-400, Cl- form, $2.4 \mathrm{~g}$ ), covering, and lightly stirring for 20 hours. Following removal of the resin by gravity filtration, the complex was isolated via rotary evaporation and purified on an aqueous Sephadex C-25 column using $0.2 \mathrm{M} \mathrm{NaCl}$ as the mobile phase (eluting as a deep red/orange band). The compound was isolated as the chloride form, after anionic exchange via treatment with Amberlite resin (IRA-400, $\mathrm{Cl}^{-}$form, $2.4 \mathrm{~g}$ ), to yield the complex as a deep red/brown microcrystalline solid. NMR spectra are shown in Figure S1.

(I) $\left[R u(T A P)_{2}(11-C N-d p p z)\right] C l_{2}$. (94 mg, $\left.0.11 \mathrm{mmol}, 74 \%\right) . \delta_{H}$ (400 MHz, $\left.\mathrm{H}_{2} \mathrm{O}-d_{2}\right)-9.74(\mathrm{~d}, J=8.4 \mathrm{~Hz}, 2 \mathrm{H}), 9.02$ (dd, $J=3.2$, $6.8 \mathrm{~Hz}, 2 \mathrm{H}), 8.99$ (d, J=3.2 Hz, 2H), $8.73(\mathrm{~s}, 1 \mathrm{H}), 8.65(\mathrm{~s}, 4 \mathrm{H})$, $8.53(\mathrm{dd}, J=7,12.4 \mathrm{~Hz}, 2 \mathrm{H}), 8.47(\mathrm{~d}, J=8.8 \mathrm{~Hz}, 1 \mathrm{H}), 8.38(\mathrm{t}, J$ $=2.0 \mathrm{~Hz}, 2 \mathrm{H}), 8.24(\mathrm{~d}, J=5.2 \mathrm{~Hz}, 2 \mathrm{H}), 8.07(\mathrm{~d}, J=8.8 \mathrm{~Hz}, 1 \mathrm{H})$ and $7.92 \mathrm{ppm}(\mathrm{dd}, J=5.2,8.8 \mathrm{~Hz}, 2 \mathrm{H})$. $\delta_{\mathrm{C}}\left(101 \mathrm{MHz}, \mathrm{H}_{2} \mathrm{O}-d_{2}\right)-$ $154.8,154.7,150.5,149.1,148.6,145.2$, 143.5, 142.6, 141.2, 135.9, 132.8, 132.2, 131.0, 130.6, 127.9 and $114.4 \mathrm{ppm}$. FT-IR 3000 (broad, m, Arom. v(-C-H)) and $2232 \mathrm{~cm}^{-1}$ (m, Nitrile v(-

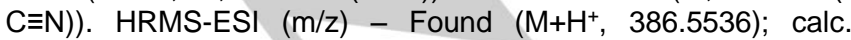
$386.5538\left(\mathrm{RuC}_{39} \mathrm{~N}_{13} \mathrm{H}_{21}{ }^{2+}\right)(\sigma<3 \mathrm{ppm})$.

(II) $\left[R u(T A P)_{2}(11, B r-d p p z)\right] C l_{2}$. (86 mg, $\left.0.10 \mathrm{mmol}, 66 \%\right) . \delta_{\mathrm{H}}$ (400 MHz, $\left.\mathrm{H}_{2} \mathrm{O}-d_{2}\right)-9.71$ (d, J = 8.3 Hz, 2H), 9.05-8.96 (m, 4H), $8.66(\mathrm{~s}, 4 \mathrm{H}), 8.57(\mathrm{~s}, 1 \mathrm{H}), 8.52(\mathrm{~d}, J=2.9 \mathrm{~Hz}, 1 \mathrm{H}), 8.47(\mathrm{~d}, J=$ $2.9 \mathrm{~Hz}, 1 \mathrm{H}), 8.37(\mathrm{t}, J=2.9 \mathrm{~Hz}, 2 \mathrm{H}), 8.32(\mathrm{~d}, J=9.1 \mathrm{~Hz}, 1 \mathrm{H})$,
8.23-8.17 $(\mathrm{m}, 2 \mathrm{H}), 8.13(\mathrm{dd}, J=9.1,2.1 \mathrm{~Hz}, 1 \mathrm{H})$ and $7.88 \mathrm{ppm}$ (ddd, $J=8.2,5.4,2.7,2 \mathrm{H})$. HRMS-ESI $(\mathrm{m} / \mathrm{z})-$ Found $\left(\mathrm{M}^{+}\right.$, 413.0119); calc. $413.0128\left(\mathrm{Ru}^{101} \mathrm{C}_{38} \mathrm{~N}_{12} \mathrm{BrH}_{21}{ }^{2+}\right)(\sigma<3 \mathrm{ppm})$.

(II) $\left[R u(T A P)_{2}(11,12-d i C N-d p p z)\right] C l_{2 .}$ ( $\left.86 \mathrm{mg}, 0.10 \mathrm{mmol}, 66 \%\right)$. $\delta_{\mathrm{H}}\left(400 \mathrm{MHz}, \mathrm{H}_{2} \mathrm{O}-d_{2}\right)-9.80(\mathrm{~d}, J=8.3 \mathrm{~Hz}, 2 \mathrm{H}), 9.07-8.90(\mathrm{~m}$, $6 \mathrm{H}), 8.68(\mathrm{~s}, 4 \mathrm{H}), 8.54(\mathrm{~d}, J=3.0 \mathrm{~Hz}, 2 \mathrm{H}), 8.40(\mathrm{~d}, J=3.0 \mathrm{~Hz}$, $2 \mathrm{H}), 8.28(\mathrm{~d}, J=5.4 \mathrm{~Hz}, 2 \mathrm{H})$ and $7.95 \mathrm{ppm}(\mathrm{dd}, J=8.4,5.4 \mathrm{~Hz}$, $2 \mathrm{H})$. $\delta_{\mathrm{c}}\left(101 \mathrm{MHz}, \mathrm{H}_{2} \mathrm{O}-d_{2}\right)-150.06,150.63,149.24,149.08$, $148.86,148.54,145.32,145.25,142.71,142.28,141.98,141.85$, $137.71,135.22,132.60,132.51,129.83,127.72,115.18$ and 114.90 ppm. FT-IR - 3051 (broad, m, Arom. v(-C-H)) and 2231 $\mathrm{cm}^{-1}(\mathrm{~m}$, Nitrile $\mathrm{v}(-\mathrm{C} \equiv \mathrm{N}))$. HRMS-ESI $(\mathrm{m} / \mathrm{z})$ - Found $\left(\mathrm{M}^{+}\right.$, 398.5519); calc. 398.5520 ( $\left(\mathrm{Ru}^{101} \mathrm{C}_{40} \mathrm{~N}_{14} \mathrm{H}_{20}{ }^{2+}\right)$ ( $\left.\sigma<3 \mathrm{ppm}\right)$.

\section{Macromolecular Crystallography}

The oligonucleotides d(TCGGCGCCGA), d(CCGGACCCGG) and d(CCGGGTCCGG) were purchased as HPLC purified solids from Eurogentec Ltd and used without further purification.

Crystallisation, data collection and analysis of $\Lambda$-(1) with d(TCGGCGCCGA) 2. Crystals containing the oligonucleotide $\mathrm{d}(\mathrm{TCGGCGCCGA})_{2}$ and ligand $\Lambda$-[Ru(TAP $\left.)_{2}(11-\mathrm{CN}-\mathrm{dppz})\right] \mathrm{Cl}_{2}$ were grown via the vapour diffusion method from sitting drops at $291 \mathrm{~K}$. Crystallisation was observed in a number of conditions from the Nucleic Acid Mini-Screen from Hampton Research, where the best diffracting example came from a $8 \mu \mathrm{L}$ drop containing; $125 \mu \mathrm{M}$ d(TCGGCGCCGA $)_{2}, 750 \mu \mathrm{M} \quad \mathrm{rac}-$ $\left[\mathrm{Ru}(\mathrm{TAP})_{2}(11-\mathrm{CN}-\mathrm{dppz})\right] \mathrm{Cl}_{2}, 7.5 \% \mathrm{v} / \mathrm{v}$ MPD, $30 \mathrm{mM} \mathrm{pH} 7$ sodium cacodylate, $9 \mathrm{mM}$ spermine tetrahydrochloride, $60 \mathrm{mM} \mathrm{KCl}$ and $15 \mathrm{mM} \mathrm{BaCl}$, all equilibrated against $500 \mu \mathrm{L}$ of $35 \% \mathrm{v} / \mathrm{v}$ MPD. Orange/red rods grew following roughly 3 weeks of incubation at $291 \mathrm{~K}$.

Diffraction data were collected from single, nitrogen flash-cooled crystal fragments at $100 \mathrm{~K}$ on beamline 102 at Diamond Light Source, Ltd. Data were automatically processed with xia2 ${ }^{[40]}$, using XDS ${ }^{[41]}$ and XSCALE to integrate and merge peaks from all collected images; yielding 5452 unique reflections. The structure was solved using single-wavelength anomalous dispersion (SAD), using the anomalous diffraction of barium, with the SHELXC/D/E package ${ }^{[42]}$. The model was built by hand, using Wincoot ${ }^{[43]}$, and refined against the original data using Refmac $5.0^{[44]}$ in the CCP4 suite ${ }^{[45]}$. Ligand restraints were calculated using eLBOW ${ }^{[46]}$ from the phenix ${ }^{[47]}$ package. As a result of the asymmetry of the intercalating ligand, two sites of non-integer occupancy are observed. This was fitted by refining the occupancy of two complete complexes in the two mirrored orientations, with the sum adding to $100 \%$ occupancy This procedure preserves the correct restraints, and also is appropriate to the actual situation in the crystal used. 5\% of reflections were reserved for the $R_{\text {free }}$ set. The final model has an $R_{\text {cryst }} / R_{\text {free }}$ of $0.16 / 0.19$ and has been deposited in the Protein Data Bank with ID 5NBE.

Crystallisation, data collection and analysis of $\Lambda$-(II) with d(TCGGCGCCGA) 2. Crystals containing the oligonucleotide $\mathrm{d}(\mathrm{TCGGCGCCGA})_{2}$ and ligand $\Lambda$-[Ru(TAP) $\left.)_{2}(11-\mathrm{Br}-\mathrm{dppz})\right] \mathrm{Cl}_{2}$ were grown via the vapour diffusion method from sitting drops at $291 \mathrm{~K}$. Crystallisation was observed in a number of conditions 
from the Nucleic Acid Mini-Screen from Hampton Research, where the best diffracting example came from a $8 \mu \mathrm{L}$ drop containing; $125 \mu \mathrm{M} \quad \mathrm{d}(\mathrm{TCGGCGCCGA})_{2}, 625 \mu \mathrm{M}$ rac$\left[\mathrm{Ru}(\mathrm{TAP})_{2}(11-\mathrm{Br}-\mathrm{dppz})\right] \mathrm{Cl}_{2}, 7.5 \% \mathrm{v} / \mathrm{v} \mathrm{MPD}, 30 \mathrm{mM} \mathrm{pH} 7$ sodium cacodylate, $9 \mathrm{mM}$ spermine tetrahydrochloride, $60 \mathrm{mM} \mathrm{KCl}$ and $15 \mathrm{mM} \mathrm{BaCl}$, all equilibrated against $500 \mu \mathrm{L}$ of $35 \% \mathrm{v} / \mathrm{v}$ MPD. Orange/red rods grew following roughly 3 weeks of incubation at $291 \mathrm{~K}$.

Diffraction data were collected from single, nitrogen flash-cooled crystal fragments at $100 \mathrm{~K}$ on beamline 103 at Diamond Light Source, Ltd. Data were automatically processed with xia2 ${ }^{[40]}$, using DIALS ${ }^{[48]}$ and Aimless ${ }^{[49]}$ to integrate and merge peaks from all collected images; yielding 16,081 unique reflections. The structure was solved using single-wavelength anomalous dispersion (SAD), using the anomalous diffraction of barium, with the SHELXC/D/E package ${ }^{[42]}$. The model was built by hand, using Wincoot ${ }^{[43]}$, and refined against the original data using Phaser ${ }^{[50]}$ in the Phenix software package ${ }^{[51]}$. Ligand restraints were calculated using eLBOW ${ }^{[46]}$ from the phenix ${ }^{[47]}$ package. As a result of the asymmetry of the intercalating ligand, two sites of non-integer occupancy are observed. This was fitted by refining the occupancy of two complete complexes in the two mirrored orientations, with the sum adding to $100 \%$ occupancy This procedure preserves the correct restraints, and also is appropriate to the actual situation in the crystal used. $5 \%$ of reflections were reserved for the $R_{\text {free }}$ set. The final model has an $R_{\text {cryst }} / R_{\text {free }}$ of $0.15 / 0.16$ and has been deposited in the Protein Data Bank with ID 6GLD.

Crystallisation, data collection and analysis of $\Lambda$-(III) with asymmetric decamer d(CCGGACCCGG)/d(CCGGGTCCGG). Crystals were grown from sitting drops by vapour diffusion at $291 \mathrm{~K}$. The drop contained the premixed and annealed duplex DNA at a concentration of $125 \mu \mathrm{M}$ $\mathrm{d}($ CCGGACCCGG)/d(CCGGGTCCGG), $125 \mu \mathrm{M} \quad \mathrm{rac}-$ $\left[\mathrm{Ru}(\mathrm{TAP})_{2}(11,12\right.$-diCN-dppz)]Cl $2,7.5 \% \mathrm{v} / \mathrm{v}$ MPD, $30 \mathrm{mM} \mathrm{pH} 7$ sodium cacodylate, $9 \mathrm{mM}$ spermine tetrahydrochloride, $60 \mathrm{mM}$ $\mathrm{KCl}$ and $15 \mathrm{mM} \mathrm{BaCl}_{2}$, equilibrated against $500 \mu \mathrm{L}$ of $35 \% \mathrm{v} / \mathrm{v}$ MPD. Orange crystals grew after several weeks. A large crystalline fragment was obtained from a larger sample using a microloop with an elongated aperture to give crystal dimensions of $60 \mu \mathrm{m} \times 30 \mu \mathrm{m} \times 100 \mu \mathrm{m})$.

Diffraction data were collected from a single, nitrogen flashcooled crystal at $100 \mathrm{~K}$ on beamline 103 at Diamond Light Source, Ltd. Data were processed with xia2, using DIALS ${ }^{[48]}$ and Aimless $^{[49]}$ to integrate and merge peaks from all collected images. The structure was solved using MR-SAD, using the anomalous diffraction of barium, with Phaser ${ }^{[50]}$ in the Phenix software package ${ }^{[51]}$. Ligand restraints were calculated using eLBOW ${ }^{[46]}$ from the phenix ${ }^{[47]}$ package. $5 \%$ of reflections were reserved for the $R_{\text {free }}$ set. The final model has an $R_{\text {cryst }} / R_{\text {free }}$ of 0.19/0.20 and has been deposited in the Protein Data Bank with ID 6G8S. Analysis of DNA dihedral angles was performed using DNATCO ${ }^{34]}$. Structural diagrams were created using PyMol (Schrödinger).

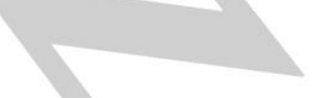

We thank Diamond Light Source and EPSRC for a studentship (to K. McQ) D.R. Allan and G. Winter (Diamond Light Source) for their supervision and generous encouragement, and BBSRC for support (to CJC, JPH, JAB and DJC), grant nos. $\mathrm{BB} / \mathrm{K} 019279 / 1$ and BB/M004635/1.

Keywords: DNA $\cdot$ ruthenium polypyridyl $\cdot \mathrm{X}$-ray crystallography $\cdot \mathrm{dppz} \cdot$ enantiospecificity

[1] A. E. Friedman, J. C. Chambron, J. P. Sauvage, N. J. Turro J. K. Barton, J. Am. Chem. Soc. 1990, 112, 4960-4962.

[2] H. Song, J. T. Kaiser, J. K. Barton, Nat. Chem. 2012, 4, 615-620.

[3] A. N. Boynton, L. Marcélis, A. J. McConnell, J. K. Barton, Inorg. Chem. 2017, 56, 8381-8389.

[4] S. Shi, X. Gao, H. Huang, J. Zhao, T. Yao, Chem. - A Eur. J. 2015, 21, 13390-13400.

[5] E. Wachter, D. Moyá, S. Parkin, E. C. Glazer, Chem. - A Eur. J. 2016, 22, 550-559.

[6] L. Jacquet, R. J. H. Davies, A. Kirsch-De Mesmaeker, J. M. Kelly, J. Am. Chem. Soc. 1997, 119, 11763-11768.

[7] L. Ghizdavu, F. Pierard, S. Rickling, S. Aury, M. Surin, D. Beljonne, R. Lazzaroni, P. Murat, E. Defrancq, C. Moucheron, et al., Inorg. Chem. 2009, 48, 10988-10994.

[8] S. Kajouj, L. Marcélis, V. Lemaur, D. Beljonne, C. Moucheron, Dalt. Trans. 2017, 46, 6623-6633.

[9] M. Rebarz, L. Marcélis, M. Menand, D. Cornut, C. Moucheron, I. Jabin, A. Kirsch-De Mesmaeker, Inorg. Chem. 2014, 53, 2635-2644.

[10] S. Le Gac, M. Foucart, P. Gerbaux, E. Defrancq, C. Moucheron, A. Kirsch-De Mesmaeker, Dalton Trans. 2010, 39, 9672-83.

[11] S. G. Bown, Philos. T. R. Soc. A. 2013, 371, 20120371.

[12] V. Pierroz, R. Rubbiani, C. Gentili, M. Patra, C. Mari, G. Gasser, S. Ferrari, Chem. Sci. 2016, 7, 6115-6124.

[13] F. Heinemann, J. Karges, G. Gasser, Acc. Chem. Res. 2017, 50, 2727-2736.

[14] C. Mari, R. Rubbiani, G. Gasser, Inorganica Chim. Acta 2017, 454, 21-26.

[15] J. Hess, H. Huang, A. Kaiser, V. Pierroz, O. Blacque, H. Chao, G. Gasser, Chem. - A Eur. J. 2017, 23, 9888-9896.

[16] F. E. Poynton, S. A. Bright, S. Blasco, D. C. Williams, J. M. Kelly, T. Gunnlaugsson, Chem. Soc. Rev. 2017, 46, 77067756 .

[17] C. Mari, V. Pierroz, S. Ferrari, G. Gasser, Chem. Sci. 2015,

\section{Acknowledgements}




\section{6, 2660-2686.}

[18] M. R. Gill, P. J. Jarman, S. Halder, M. G. Walker, H. K Saeed, J. A. Thomas, C. Smythe, K. Ramadan, K. A. Vallis, Chem. Sci. 2018, 9, 841-849.

[19] B. C. Poulsen, S. Estalayo-Adrián, S. Blasco, S. A. Bright, J. M. Kelly, D. C. Williams, T. Gunnlaugsson, B. la Cour Poulsen, S. Estalayo-Adrian, S. Blasco, et al., Biophys. Chem. 2016, 45, 18208-18220.

[20] S. M. Cloonan, R. B. P. Elmes, M. Erby, S. A. Bright, F. E. Poynton, D. E. Nolan, S. J. Quinn, T. Gunnlaugsson, D. C. Williams, J. Med. Chem. 2015, 58, 4494-4505.

[21] E. Wachter, D. Moyá, E. C. Glazer, ACS Comb. Sci. 2017 19, 85-95.

[22] I. Ortmans, B. Elias, J. M. Kelly, C. Moucheron, A. KirschDeMesmaeker, Dalton Trans. 2004, 2, 668-676.

[23] P. M. Keane, J. M. Kelly, Coord. Chem. Rev. 2018, 364, 137-154.

[24] J. P. Hall, K. O'Sullivan, A. Naseer, J. A. Smith, J. M. Kelly, C. J. Cardin, Proc. Natl. Acad. Sci. 2011, 108, 1761017614.

[25] H. Niyazi, J. P. Hall, K. O'Sullivan, G. Winter, T. Sorensen, J. M. Kelly, C. J. Cardin, Nat. Chem. 2012, 4, 621-628.

[26] J. P. Hall, D. Cook, S. R. Morte, P. McIntyre, K. Buchner, H. Beer, D. J. Cardin, J. A. Brazier, G. Winter, J. M. Kelly, et al., J. Am. Chem. Soc. 2013, 135, 12652-12659.

[27] P. M. Keane, J. P. Hall, F. E. Poynton, B. C. Poulsen, S. P. Gurung, I. P. Clark, I. V. Sazanovich, M. Towrie, T. Gunnlaugsson, S. J. Quinn, et al., Chem. - A Eur. J. 2017, 23, 10344-10351.

[28] J. P. Hall, S. P. Gurung, J. Henle, P. Poidl, J. Andersson, P. Lincoln, G. Winter, T. Sorensen, D. J. Cardin, J. A. Brazier, et al., Chem. - A Eur. J. 2017, 23, 4981-4985.

[29] C. J. Cardin, J. M. Kelly, S. J. Quinn, Chem. Sci. 2017, 8, $4705-4723$.

[30] J. P. Hall, H. Beer, K. Buchner, D. J. Cardin, C. J. Cardin, Philos. Trans. A. Math. Phys. Eng. Sci. 2013, 371, 20120525.

[31] P. M. Keane, F. E. Poynton, J. P. Hall, I. V. Sazanovich, M. Towrie, T. Gunnlaugsson, S. J. Quinn, C. J. Cardin, J. M. Kelly, Angew. Chemie - Int. Ed. 2015, 54, 8364-8368.

[32] J. P. Hall, F. E. Poynton, P. M. Keane, S. P. Gurung, J. A. Brazier, D. J. Cardin, G. Winter, T. Gunnlaugsson, I. V. Sazanovich, M. Towrie, et al., Nat. Chem. 2015, 7, 961967.

[33] J. P. Hall, J. Sanchez-Weatherby, C. Alberti, C. H. Quimper, K. O'Sullivan, J. A. Brazier, G. Winter, T. Sorensen, J. M. Kelly, D. J. Cardin, et al., J. Am. Chem. Soc. 2014, 136, 17505-17512.
[34] B. Schneider, P. Božíková, I. Nečasová, P. Čech, D. Svozil, J. Černý, Acta Crystallogr. Sect. D Struct. Biol. 2018, 74, 52-64.

[35] J. P. Hall, H. Beer, K. Buchner, D. J. Cardin, C. J. Cardin, Organometallics 2015, 34, 2481-2486.

[36] A. N. Boynton, L. Marcélis, J. K. Barton, J. Am. Chem. Soc. 2016, 138, 5020-5023.

[37] J. P. Hall, P. M. Keane, H. Beer, K. Buchner, G. Winter, T. L. Sorensen, D. J. Cardin, J. A. Brazier, C. J. Cardin, Nucleic Acids Res. 2016, 44, 9472-9482.

[38] A. K. F. Mårtensson, P. Lincoln, Phys. Chem. Chem. Phys. 2018, 20, 7920-7930.

[39] M. Dik-Lung, C. M. Che, S. C. Yan, J. Am. Chem. Soc. 2009, 131, 1835-1846.

[40] G. Winter, J. Appl. Crystallogr. 2010, 43, 186-190.

[41] W. Kabsch, Acta Crystallogr. Sect. D Biol. Crystallogr. 2010 $66,125-132$

[42] G. M. Sheldrick, Acta Crystallogr. Sect. D Biol. Crystallogr. 2010, 66, 479-485.

[43] P. Emsley, B. Lohkamp, W. G. Scott, K. Cowtan, Acta Crystallogr. Sect. D Biol. Crystallogr. 2010, 66, 486-501.

[44] G. N. Murshudov, P. Skubák, A. A. Lebedev, N. S. Pannu, R. A. Steiner, R. A. Nicholls, M. D. Winn, F. Long, A. A. Vagin, Acta Crystallogr. Sect. D Biol. Crystallogr. 2011, 67, 355-367.

[45] M. D. Winn, C. C. Ballard, K. D. Cowtan, E. J. Dodson, P. Emsley, P. R. Evans, R. M. Keegan, E. B. Krissinel, A. G. W. Leslie, A. McCoy, et al., Acta Crystallogr. Sect. D Biol. Crystallogr. 2011, 67, 235-242.

[46] N. W. Moriarty, R. W. Grosse-Kunstleve, P. D. Adams, Acta Crystallogr. Sect. D Biol. Crystallogr. 2009, 65, 1074-1080.

[47] P. D. Adams, P. V. Afonine, G. Bunkóczi, V. B. Chen, I. W. Davis, N. Echols, J. J. Headd, L. W. Hung, G. J. Kapral, R. W. Grosse-Kunstleve, et al., Acta Crystallogr. Sect. D Biol. Crystallogr. 2010, 66, 213-221.

[48] J. M. Parkhurst, G. Winter, D. G. Waterman, L. FuentesMontero, R. J. Gildea, G. N. Murshudov, G. Evans, J. Appl. Crystallogr. 2016, 49, 1912-1921.

[49] P. R. Evans, G. N. Murshudov, Acta Crystallogr. Sect. D Biol. Crystallogr. 2013, 69, 1204-1214.

[50] A. J. McCoy, R. J. Read, Acta Crystallogr. Sect. D Biol. Crystallogr. 2010, 66, 458-469.

[51] P. D. Adams, R. W. Grosse-Kunstleve, L. W. Hung, T. R. loerger, A. J. McCoy, N. W. Moriarty, R. J. Read, J. C. Sacchettini, N. K. Sauter, T. C. Terwilliger, et al., Acta Crystallogr. Sect. D Biol. Crystallogr. 2002, 58, 1948-54. 


\section{Entry for the Table of Contents}

\section{FULL PAPER}
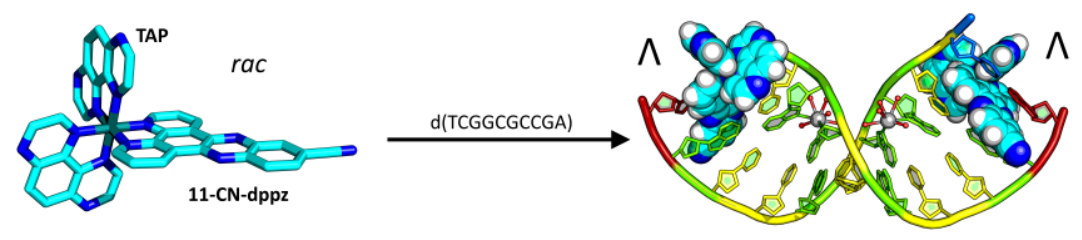

Addition of one or two terminal nitrile groups to the dppz ligand improves the stacking capability of the ligand, shown by the formation of a closed intercalation cavity.
Kane McQuaid, James P. Hall, John A.

Brazier, David J. Cardin and Christine J. Cardin*

Page No. - Page No.

$X$-ray crystal structures show DNA stacking advantage of terminal nitrile substitution in Ru-dppz complexes 